BMJ Open Sport \& Exercise Medicine

\title{
How do orthopaedic surgeons and rehabilitation professionals interpret and assess 'toe touch' weight bearing and 'partial' weight bearing status in the rehabilitation setting?
}

\author{
Stephen G Thompson, Rhodri D Phillip, Andrew Roberts
}

To cite: Thompson SG, Phillip R D, Roberts A. How do orthopaedic surgeons and rehabilitation professionals interpret and assess 'toe touch' weight bearing and 'partial' weight bearing status in the rehabilitation setting? BMJ Open Sport \& Exercise Medicine 2018;4:e000326. doi:10.1136/ bmjsem-2017-000326

Accepted 9 February 2018
Check for updates

Defence Medical Rehabilitation Centre, Headley Court, Epsom, United Kingdom

Correspondence to Stephen G Thompson; stephen. thompson84@gmail.com

\section{ABSTRACT}

Aim To compare the interpretation of toe touch weight bearing (TTWB) and partial weight bearing (PWB) among orthopaedic surgeons, rehabilitation professionals and patients.

Methodology 78 consultant and middle-grade orthopaedic surgeons in the UK completed a questionnaire. 64 rehabilitation professionals (including physiotherapists) at Defence Medical Rehabilitation Centre Headley Court were also recruited. Both groups provided their interpretation of TTWB and PWB as a percentage of total body weight (\%TBW). Each rehabilitation professional, then applied what they interpreted to be TTWB and PWB using a Lasar Posture weighing device. The predicted values were compared with the actual values demonstrated.

Results There was no significant difference between orthopaedic surgeons and rehabilitation professionals in their interpretation of TTWB and PWB, however there was a wide range of responses. There was a significant difference between the predicted \%TBW and the actual values demonstrated by the 'educated patient' (mean difference 4.8 (TTWB) and 22.9 (PWB)).

Conclusion Healthcare professionals vary greatly in their interpretation of the terms TTWB and PWB. Therefore, for a consistency in rehabilitation delivery the terms should not be used in isolation without a further descriptor. Static measures of weight application are lower than people think they are applying. We encourage the use of loading practice with a scale to reassure and educate patients.

\section{BACKGROUND AND SIGNIFICANCE}

One of the most important concepts in orthopaedics is that prolonged mobility restriction has a negative effect on the healing of bone and the surrounding soft tissues. ${ }^{1}$ Furthermore, loading has anabolic effects on bone strength and mass. ${ }^{2}$ Multiple clinical trials have established the benefits of early loading on fracture healing if stress at the fracture site is controlled. ${ }^{13}$ However, too much stress during fracture healing can lead to delayed healing or non-union. Therefore, a

\section{Key messages}

- There is a great variation in the interpretation of the terms toe touch weight bearing and partial weight bearing (PWB) between healthcare professionals managing lower limb injuries. For a consistency in rehabilitation delivery the terms should not be used in isolation without a further descriptor (ie, PWB at $40 \%)$.

- Static measures of weight application are lower than people think they are applying. The findings may impact on weight-bearing prescription following lower limb injuries/fractures and the assessment and education of patients in the rehabilitation setting.

- The study supports the exploration of dynamic measures to educate and assess weight-bearing status.

balance must be reached between the appropriate rest period and initiating early controlled loading for fracture healing.

Musculoskeletal injuries are among the most common medical reasons for lost time at work and within training in the military population. Minimising the duration of military patients' activity restriction may decrease muscular atrophy, improve neuromuscular re-education ${ }^{1}$ and lead to quicker return to full activity and duty. ${ }^{4}$ Therefore, it would be useful to understand what orthopaedic surgeons believe they are prescribing and what it means to patients in practice.

Orthopaedic surgeons often prescribe an incremental increase in weight-bearing status following a lower limb fracture or injury. Many different terms are used to help guide the rehabilitation. Terms such as non-weight bearing, toe touch weight bearing (TTWB), flat foot feather touch weight bearing, egg shell weight bearing, partial weight bearing (PWB) and full weight bearing are often used. 
In this study, we explored the terms TTWB and PWB. Both terms are ill-defined. TTWB is generally considered as $20 \%$ total body weight $(\mathrm{TBW})^{5}$ or $10-15 \mathrm{~kg}^{6}{ }^{6}$ Most authors use a definition of PWB as $30 \%-50 \% \mathrm{TBW}^{7}$ or $20-25 \mathrm{~kg}^{6}{ }^{6} \mathrm{At}$ Defence Medical Rehabilitation Centre (DMRC), Headley Court we noted that the interpretation of TTWB and PWB varied among the orthopaedic community. This finding is consistent with the ill-defined definitions in the literature. ${ }^{8}$

Patient understanding of the terms TTWB and PWB also varies greatly. The ability of a patient to achieve accurate weight-bearing levels has been explored previously. ${ }^{9} 10$ Methods used to educate and assess the ability to replicate a certain weight-bearing status have included bathroom scales, ${ }^{11}$ force plates,${ }^{12}$ insole measuring pressure devices, ${ }^{13}$ limb load monitors ${ }^{14}$ and biofeedback. ${ }^{5}$ In the rehabilitation setting, weighing scales are commonly used to educate patients on weight-bearing status. Ebert et $a l^{15}$ found that patients were unable to follow weightbearing restrictions after instruction and practice on a set of scales, and patients were unable to replicate weightbearing levels in both static and dynamic conditions.

Therefore, we aimed to compare the interpretation of TTWB and PWB in orthopaedic surgeons and rehabilitation professionals dealing with lower limb injuries. We also examined the healthcare professional's understanding of TTWB and PWB compared with an educated patient's understanding in practice.

\section{METHODOLOGY}

A simple questionnaire was created on SurveyMonkey asking for an interpretation of TTWB and PWB as a percentage of total body weight (\% TBW) from a dropdown box with options ranging from $0 \%$ to $100 \%$. The respondents were also asked for their employment grade and given the opportunity to provide additional comments. The questionnaire was distributed via email nationally through various orthopaedic specialist registrar and consultant mailing lists. Responses were accepted from both military and civilian consultants and specialist registrars at a grade of ST4 and above. Both questions must have been completed for inclusion. Seventy-eight consultant and middle-grade orthopaedic surgeons who met the inclusion criteria completed the questionnaire.

'Rehabilitation professionals' managing lower limb injuries on a daily basis at DMRC Headley Court were recruited; including physiotherapists, doctors, exercise rehabilitation instructors, nurses and occupational therapists. Rehabilitation professionals managing upper limb and spinal patients were excluded from the study. Participants with any musculoskeletal, neurological or medical problem which may impact on weight bearing or the perception of load were also excluded. Sixty-four rehabilitation professionals met the inclusion criteria to participate in the study. Written consent was sought from each participant prior to involvement in the study. Each participant was asked for their interpretation of TTWB and PWB as a \%TBW. Each individual was then weighed using a calibrated Ottobock Lasar Posture device, acting simply as an accurate weighing scale.

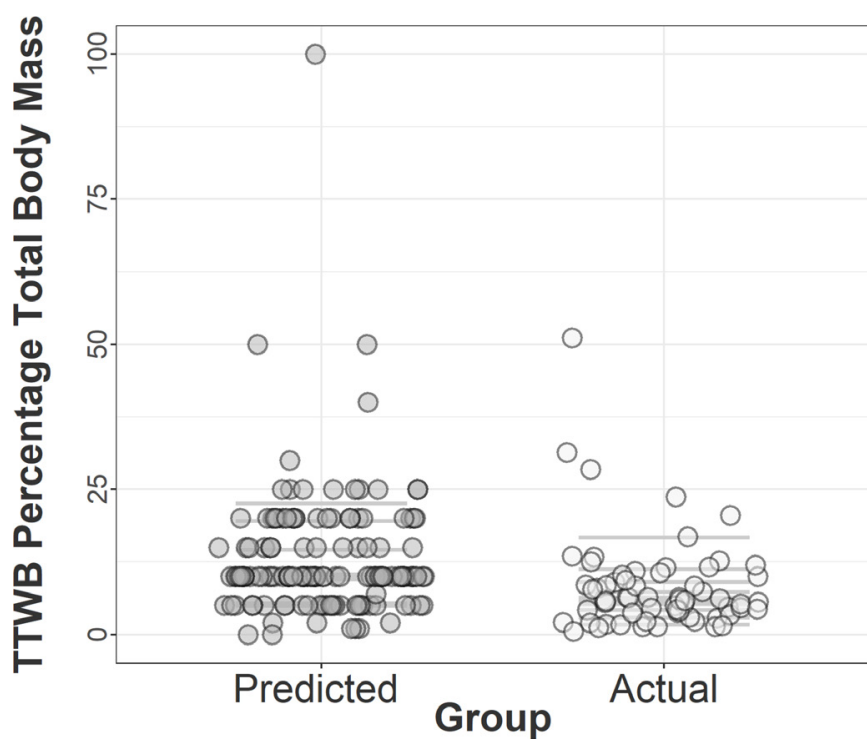

Figure 1 Predicted \%TBW by orthopaedic surgeons and rehabilitation professionals, and actual values demonstrated by the 'educated patient' for TTWB. \%TBW, percentage of total body weight; TTWB, toe touch weight bearing.

Each participant was asked to apply what they interpreted to be TTWB and PWB through one lower limb while using crutches as an aid. The process was repeated on each lower limb, alternating between each side three times. Participants were blinded to the readings.

SPSS V.24 software (IBM Corp 2016) was used to analyse the data collected. Bootstrapped t-tests, which do not assume an underlying distribution, were run to compare the mean predicted \% TBW between orthopaedic surgeons and rehabilitation professionals for TTWB and PWB, and to compare the predicted values with the actual values demonstrated. A P value of 0.05 was considered statistically significant.

\section{RESULTS}

\section{Orthopaedic versus rehabilitation professional interpretation} of TTWB and PWB

There was no significant difference between orthopaedic surgeons and rehabilitation professionals in their interpretation of TTWB (mean 13.7 and 12.1, respectively, $\mathrm{P}=0.38$ ) and PWB (mean 44.9 and 40.7, respectively, $\mathrm{P}=0.08$ ). There was marked variability in the interpretation of TTWB in the orthopaedic group compared with the rehabilitation group (SD 13.7 and 6.5, respectively) (see figure 1), however not for PWB (SD 15.4 and 12.2, respectively) (see figure 2).

\section{Dominant versus non-dominant application of TTWB and PWB}

There was no significant difference between dominant and non-dominant sides when applying TTWB (mean 8.2 and 8.7, respectively, $\mathrm{P}=0.58$ ) and $\mathrm{PWB}$ (mean 20.1 and 20.1, respectively, $\mathrm{P}=0.96)$.

\section{Predicted interpretation of TTWB and PWB compared with actual demonstration}

As there was no significant difference between orthopaedic surgeons and rehabilitation professionals in their 


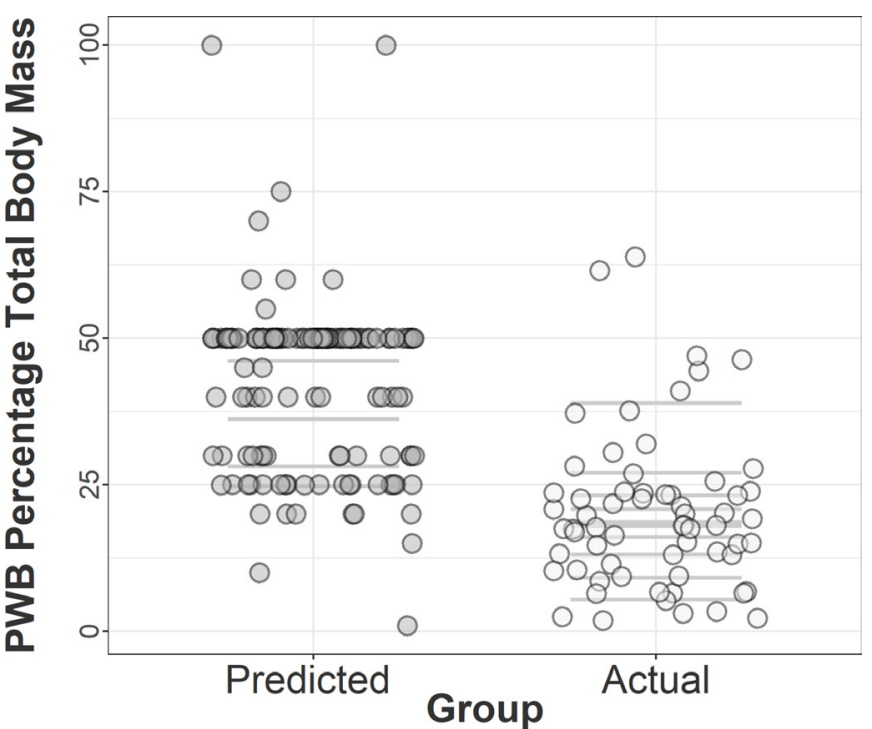

Figure 2 Predicted \%TBW by orthopaedic surgeons and rehabilitation professionals, and actual values demonstrated by the 'educated patient' for PWB. PWB, partial weight bearing; \%TWB, percentage of total body weight.

interpretation of TTWB and PWB they were considered as a single entity when comparing predicted values and actual values demonstrated by the 'educated patient'. Furthermore, as there was no significant difference between dominant and non-dominant limbs, the dominant limb was used for comparison with predicted values.

There was a significant difference between the predicted \%TBW for TTWB ( $\mathrm{n}=142$, mean 13.0) and the actual values demonstrated by the rehabilitation professional acting as an 'educated patient' ( $\mathrm{n}=64$, mean $8.2, \mathrm{P}=0.00$ ) (see figure 1).

There was a significant difference between predicted \% TBW for PWB (n=142, mean 43.0) and the actual values demonstrated by the rehabilitation professional acting as an 'educated patient' $(\mathrm{n}=64$, mean 20.1, $\mathrm{P}=0.00)$ (see figure 2).

\section{DISCUSSION}

The mean difference between orthopaedic surgeons and rehabilitation professionals' interpretation of weightbearing status was not significant for TTWB (mean difference 1.6) or PWB (mean difference 4.1). The interpretation of PWB (mean 43.0) was consistent with the $30 \%-50 \%$ stated in the literature. ${ }^{7}$

The interpretation of TTWB (mean 13.0) was lower than the $20 \%$ stated in the few studies available in the literature. ${ }^{5}$ Interestingly in the present study the term 'like walking on egg shells' was commonly quoted by both surgeons and rehabilitation professionals when referring to TTWB.

The variability between healthcare professionals when interpreting TTWB and PWB is a significant feature (see figure 1). Orthopaedic surgeons and other allied healthcare professionals (AHPs) appear to interpret TTWB and PWB anywhere in the range from $1 \%$ to $100 \%$ TBW. This variation is consistent with the anecdotal evidence at DMRC Headley Court. Two patients could have very different rehabilitation pathways if prescribed TTWB and PWB dependent on the interpretation of the healthcare professional prescribing the weight-bearing status and the understanding of the various AHPs delivering the rehabilitation.

Although weight-bearing status is prescribed and guided by orthopaedic surgeons and rehabilitation AHPs, the understanding of the patient in the terms used is also important in the implementation of a rehabilitation programme. In this study rehabilitation professionals at Headley Court were recruited to effectively act as educated patients to demonstrate what they interpreted as TTWB and PWB on a set of weighing scales (Ottobock's Lasar Posture) in a static position, using crutches. The use of weighing scales is a commonly used method in the rehabilitation setting to guide the patient with weight-bearing progression.

There was a significant difference between TTWB and PWB status as predicted by orthopaedic surgeons and AHPs when compared with the 'educated patient' demonstrating TTWB and PWB in the static position (mean difference 4.8 (TTWB) and 22.9 (PWB)). The findings demonstrate that when static weighing scales were used to demonstrate weight-bearing status the force applied was significantly lower than that predicted/prescribed. This highlights a potential mismatch between what a patient thinks they are applying versus what they are actually applying. The reason for the mismatch could be because static measures are very different to dynamic, or because people truly under weight bear. Therefore, if scales are to be used it encourages the use of loading practice to reassure and educate how much force a patient can actually put through a limb. Further research is required in this area to evaluate dynamic techniques, such as the use of force plates to analyse the forces applied at various points in the gait cycle, and how the results compare with static measures in the clinical setting.

Given the variability seen in this study in direction and interpretation there is the potential, using current technologies, to apply a more controlled progression in weight-bearing activity postfracture. DMRC Headley Court has access to Alter-G treadmills. The Alter-G treadmill is an Food and Drug Administration approved tool that allows patients to be exercised at body weight percentages from $1 \%$ to $100 \%$ in $1 \%$ increments in a tightly controlled environment. ${ }^{16}$

\section{CONCLUSION}

There is a great variation in the interpretation of the terms TTWB and PWB between healthcare professionals managing lower limb injuries. To ensure consistency in rehabilitation delivery the terms should not be used in isolation without a further descriptor (ie, PWB at 40\%).

Static measures were lower than people thought they were applying. This could be because static application of weight is very different to dynamic or because people truly under weight bear. This encourages the use of loading practice with a scale to reassure and 
educate how much they can actually put through a limb. Further work to determine methods of assessing dynamic measuring of weight bearing in clinical settings would be of value, as well as comparing these with static measures such as that used in this study.

Acknowledgements The authors would like to thank the orthopaedic surgeons for taking the time to complete the survey distributed for the purposes of this study, and all the rehabilitation staff at DMRC Headley Court who contributed to the study.

Funding This research received no specific grant from any funding agency in the public, commercial or not-for-profit sectors.

Competing interests None declared.

Ethics approval In accordance with Ministry of Defence (MoD) research ethics guidelines, this study was exempt from requiring formal MoD ethical approval.

Provenance and peer review Not commissioned; externally peer reviewed.

Open Access This is an Open Access article distributed in accordance with the Creative Commons Attribution Non Commercial (CC BY-NC 4.0) license, which permits others to distribute, remix, adapt, build upon this work non-commercially, and license their derivative works on different terms, provided the original work is properly cited and the use is non-commercial. See: http://creativecommons.org/ licenses/by-nc/4.0/

(C) Article author(s) (or their employer(s) unless otherwise stated in the text of the article) 2018. All rights reserved. No commercial use is permitted unless otherwise expressly granted.

\section{REFERENCES}

1. Buckwalter JA, Grodzinsky AJ. Loading of healing bone, fibrous tissue, and muscle: implications for orthopaedic practice. J Am Acad Orthop Surg 1999; 7:291-9.
2. Turner $\mathrm{CH}$, Robling $\mathrm{AG}$. Mechanisms by which exercise improves bone strength. J Bone Miner Metab 2005;23:16-22.

3. Sarmiento A, Schaeffer JF, Beckerman L, et al. Fracture healing in rat femora as affected by functional weight-bearing. J Bone Joint Surg Am 1977;59:369-75

4. Moore MN, Vandenakker-Albanese C, Hoffman MD. Use of partial body-weight support for aggressive return to running after lumbar disk herniation: a case report. Arch Phys Med Rehabil 2010;91:803-5.

5. Hershko E, Tauber C, Carmeli E. Biofeedback versus physiotherapy in patients with partial weight-bearing. Am J Orthop 2008;37:E92-6.

6. Ruedi TP, Buckley RE, Moran CG. AO Principles of Fracture Management. New York, NY: Thieme, 2007.

7. Bohannon RW, Waters G, Cooper J. Perception of unilateral lower extremity weightbearing during bilateral upright stance. Percept Mot Skills 1989;69:875-80.

8. Rubin G, Monder O, Zohar R, et al. Toe-touch weight bearing: myth or reality? Orthopedics 2010;33:729.

9. Dabke HV, Gupta SK, Holt CA, et al. How accurate is partial weightbearing? Clin Orthop Relat Res 2004;421:282-6.

10. Malviya A, Richards J, Jones RK, et al. Reproducibility of partial weight bearing. Injury 2005;36:556-9.

11. Schaefer L, Bohannon RW. Perception of unilateral weightbearing during unilateral and bilateral upright stance. Percept Mot Skills 1990;71:123-8

12. Gray FB, Gray C, McClanahan JW. Assessing the accuracy of partial weight-bearing instruction. Am J Orthop 1998;27:558-60.

13. Tveit M, Kärrholm J. Low effectiveness of prescribed partial weight bearing. Continuous recording of vertical loads using a new pressure-sensitive insole. J Rehabil Med 2001;33:42-6.

14. Gapsis JJ, Grabois M, Borrell RM, et al. Limb load monitor: evaluation of a sensory feedback device for controlled weight bearing. Arch Phys Med Rehabil 1982;63:38-41.

15. Ebert JR, Ackland TR, Lloyd DG, et al. Accuracy of partial weight bearing after autologous chondrocyte implantation. Arch Phys Med Rehabil 2008;89:1528-34.

16. Alter-G Incorporated. $510 \mathrm{~K}$ Summary. 2007. https://www. accessdata.fda.gov/cdrh docs/pdf7/K072887.pdf (accessed $11 \mathrm{Jul}$ 2017) 